\title{
OS DIREITOS HUMANOS NO CONTEXTO INTERNACIONAL: PARA ALÉM DOS LIMITES DE UMA OBRIGAÇÃO ESPECÍFICA?
}

\author{
HUMAN RIGHTS ON THE INTERNATIONAL CONTEXT: BEYOND THE LIMITS OF A SPECIFIC \\ OBLIGATION?
}

André Luiz Olivier da Silva ${ }^{1}$

Resumo: Neste trabalho analisam-se as exigências por direitos humanos enunciados a partir de uma perspectiva universal, segundo a qual esses direitos se constituem dentro de obrigações gerais e são válidos para todas as pessoas do mundo. Mas podemos falar em direitos humanos considerados gerais e absolutos mesmo quando não se consegue especificar o detentor e o destinatário dos direitos em uma relação obrigacional específica? Com base em um procedimento de observação e na explicitação de algumas exigências por direitos humanos no mundo contemporâneo, aborda-se a natureza dos direitos a partir da correlação obrigacional entre direitos e deveres, bem como a distinção entre direitos especiais e direitos gerais, destacando que os direitos humanos são reivindicados como direitos gerais e universais, embora não se possa afirmar que sejam universais em si mesmos. A hipótese neste artigo é a de que os direitos humanos são reivindicados "como se" fossem "gerais" dentro de obrigações específicas, seja em um conflito entre cidadãos e o Estado, seja a partir das relações dos países na comunidade internacional. Quando não estão especificados em obrigações concretas, esses direitos apresentam dificuldades quanto à sua efetividade justamente porque não se consegue identificar e especificar sujeitos e destinatários - que não são exatamente o Estado ou o cidadão deste ou daquele país, mas, sim, a pessoa humana. Nesse sentido, ainda estamos longe do ideal de universalização dos direitos humanos na comunidade internacional, e esses direitos só podem ser exercidos quando incorporados a um ordenamento jurídico ou, ao menos, inseridos em práticas morais e sociais.

Palavras-chave: Direitos humanos. Direitos gerais. Universalidade. Obrigações específicas.
Abstract: This paper discusses the claims by human rights from a universal perspective, according to which human rights constitute general obligations and are valid for all people of the world. Can we talk about human rights considered general and valid for all human beings even when we can not specify the holder and the addressee of rights in a specific obligational relationship? Based on a procedure of observation and explanation of some claims for human rights in the contemporary world, this article aims to approach the nature of these rights from the obligational correlation between rights and duties, as well as the distinction between special rights and general rights, highlighting that human rights are claimed as general rights, emphasizing its "universal" character, although we can't ensure that these rights are universal in themselves. Our hypothesis is that human rights are claimed "as if" they were "general" within specific obligations, whether in a conflict between citizens and the state, as based on the relations of countries in the international community. When not specified in concrete obligations, human rights have doubts as to its effectiveness precisely because it is not easy to identify and specify recipients and subject of rights - which are not exactly state or country, but rather the human person. In this sense, we are still far from the ideal of universal human rights in the international community, and these rights may be exercised only when incorporated into a law, or at least, embedded in moral and social practices.

Keywords: Human Rights. General rights. Universality. Specific obligations.

\footnotetext{
1 Doutor em Filosofia pela Universidade do Vale do Rio dos Sinos; Mestre em Filosofia pela Universidade do Vale do Rio dos Sinos; Professor nos Cursos de Direito e de Relações Internacionais da Universidade do Vale do Rio do Sinos; Coordenador do Curso de Graduação em Direito da Universidade do Vale do Rio do Sinos; andreluiz@unisinos.br
} 


\section{Introdução}

No presente texto analisam-se as exigências e reivindicações por direitos humanos no mundo contemporâneo, ao tentar entender como podemos reivindicar direitos a partir de uma perspectiva universal e absoluta, segundo a qual os direitos humanos ultrapassariam os limites de uma obrigação específica para se constituírem como os direitos gerais que todos possuiriam e que contra todos pudessem ser reivindicados. Em um primeiro momento, pretendemos mostrar que os direitos se constituem a partir de obrigações, que podem ser tanto obrigações específicas e restritas aos dois polos da relação obrigacional quanto obrigações gerais, que se constituem na medida em que os direitos são produzidos para além dos limites de uma obrigação específica, quando se fala em direitos que são de todos e aos quais todos devem respeito. No caso dessas obrigações de cunho geral, os direitos contidos na relação são denominados ius in rem no sentido de que são direitos que podem ser cobrados contra toda e qualquer pessoa do mundo, isto é, são direitos contra o mundo.

Após explicar que os direitos humanos se constituem como esses direitos válidos para todos, como se fossem universais e absolutos, o presente trabalho questiona o sentido de falarmos em direitos que são de todos em razão de uma característica essencial contida em todo o ser humano, a saber, a nossa humanidade. $\mathrm{O}$ que se quer mostrar com essa discussão é que os direitos humanos, ao serem reivindicados como direitos gerais, apresentam dificuldades quanto à especificação dos polos da relação obrigacional e não conseguem mostrar quem os possui enquanto detentor ou sujeito de direito e quem os deve cumprir para torná-los efetivos. Esses direitos gerais dependem, para serem exercidos na vida prática dos homens, ou da sua efetividade nas relações morais e sociais, ou, então, de um ordenamento jurídico que os transforme em direitos fundamentais positivados em texto constitucional.

\section{As obrigações e a relação entre direitos e deveres}

Os direitos surgem a partir das obrigações que os seres humanos tecem entre si, seja porque o Estado assim o exige, seja pelo simples fato de que não conseguem viver à margem dos vínculos sociais e carecem de pequenos acordos para garantir a sua sobrevivência. As obrigações relacionam duas partes em um jogo entre direitos e deveres, segundo o qual um dos polos possui um direito, ao passo que o outro deve cumprir uma obrigação. Em geral, as obrigações podem ser entendidas como promessas, acordos e contratos estabelecidos entre duas partes, que podem ser uma pessoa física, uma empresa ou um Estado diante da comunidade internacional.

As obrigações podem ser de dois tipos, especiais e gerais, na medida em que conseguem ou não especificar as partes da relação obrigacional. As obrigações especiais apresentam tanto o polo ativo quanto o passivo da relação jurídica, de modo que, nessas obrigações, não é difícil identificar o detentor do direito concedido e o seu respectivo destinatário. Já no caso das obrigações gerais, tanto o sujeito de direito quanto o seu destinatário podem ser indeterminados (ou, ao menos, temporaria- 
mente indetermináveis), visto que estamos diante dos denominados direitos in rem, isto é, direitos que são válidos para e contra todos, como é o caso dos direitos humanos. Os direitos humanos são enunciados a partir de uma perspectiva universalista e deixam o seguinte problema em aberto: como podem existir direitos gerais se não conseguimos especificar os polos da relação jurídica?

\subsection{0 ato de prometer}

Os direitos são concedidos mutuamente entre as pessoas, quando, por exemplo, aliena-se um bem, quando se troca ou se empresta uma coisa para outra pessoa, quando, enfim, estabelece-se uma relação jurídica entre elas. ${ }^{2}$ Nesse caso, uma das partes outorga um direito à outra para usufruir a coisa, desde que essa coisa seja devolvida após um lapso de tempo ou alguma condição seja respeitada. Os direitos são também outorgados pelo Estado para viabilizar a satisfação dos interesses entre os seus cidadãos e, a partir de um contrato social, direitos são concedidos ao cidadão, que poderá reivindicá-los contra os seus governantes. No fundo, podemos entender melhor a concessão de um direito a partir da "promessa", ou do ato de prometer, quando alguém - um homem ou um Estado Soberano - se compromete, por meio de um ato linguístico, a realizar algo em um tempo futuro e em benefício de terceiros.

Os direitos nascidos das promessas devem ser, para existirem juridicamente, específicos e estarem restritos a uma obrigação especial composta por duas partes existentes e individualizadas. Hart (1955, p. 183, tradução nossa) ${ }^{3}$ aborda isso e diz que: "Os casos mais evidentes de direitos especiais são aqueles que surgem a partir de promessas." (HART, 1955, p. 183, tradução nossa). O promitente dá, por certo, a sua palavra, comprometendo-se e, no ato de prometer, outorga, objetivamente, um direito ${ }^{4}$ ao outro, e a ele fica enlaçado, amarrado, sendo necessário ao promitente, para desenlaçar o nó que une as partes, satisfazer o que restou prometido, conforme esclarece Tugendhat (2003, p. 337): "Se alguém me prometeu algo, eu tenho objetivamente o direito - o direito subjetivo - de que ele cumpra a promessa." Nesse ponto, autores como Hare ${ }^{5}$ e Tugendhat definiram a obrigação prometida, respectivamente, como o "jogo da promessa" (HARE, 1967, p. 115), "um jogo de conceder e assumir um direito." (TUGENDHAT, 2003, p. 337). As crianças aprendem esse jogo à

\footnotetext{
2 Nesse caso, estamos a nos referir ao Direito Civil, pois é discutível que essa seja a origem do Direito Penal. Promessas se constituem como a origem do Direito Civil, embora até possam ser relacionadas ao Direito Penal. De certo modo, as teorias contratualistas reduziram toda a discussão dos direitos ao modelo do Direito Civil, principalmente por causa da propriedade privada.

3 "The most obvious cases of special rights are those that arise from promises." (HART, 1955, p. 183).

4 Nesse sentido, compreende-se porque os direitos humanos são considerados direitos morais por autores como Feinberg (1992), pois a significação do termo "direito" (humano) corresponde às obrigações de cunho estritamente moral, que se traduzem na promessa. Afirma Bobbio (2004, p. 8): "Não há direito sem obrigação; e não há nem direito nem obrigação sem uma norma de conduta. A não usual expressão 'direitos morais' torna-se menos estranha quando é relacionada com a usadíssima expressão 'obrigações morais'. [...] mas, quando se introduz a noção de "direito moral”, introduz também, necessariamente, a correspondente 'obrigação moral'. Ter direito moral em face de alguém significa que há um outro indivíduo que tem obrigação moral para comigo."

5 Ver também Gilbert (2004, p. 83-109).
} 
medida que compreendem o que significa ter um direito ao mesmo tempo em que se pode abrir mão e renunciá-lo, conforme afirma Tugendhat (2003, p. 339):

Como a criança aprende aquilo que se quer dizer com a expressão "eu prometo"? A mãe tentaria explicar para a criança que quando ela emprega este termo, ela dá à criança a autorização de exigir o cumprimento da promessa. E a criança pode aprender a fazer o mesmo. A mãe - falando em linguagem figurada - dá à criança uma rédea na mão, na qual ela se amarrou; e a criança agora aprende que pode puxar a rédea conforme deseja, mas que também pode soltá-la. Esta última possibilidade designamos como renúncia ao cumprimento da exigência do direito (no inglês existe para isto uma palavra própria: to waive one's rigth).

O funcionamento do jogo pode nos ajudar a entender o modo como um direito é concedido, pois o jogo, para ser compreendido, precisa existir dentro de um sistema de regras que estabeleça direitos e deveres recíprocos. A ideia de jogo nesse ponto é mencionada apenas por uma analogia aos jogos, a fim de que possamos metaforicamente entender tais empreendimentos guiados por regras. Mas é não mais do que uma analogia. Jogos são atividades guiadas por regras cuja existência serve apenas para tornar o jogo possível. São obstáculos, barreiras artificialmente criados para possibilitar as jogadas e os movimentos que as partes podem colocar em prática visando à diversão.

O problema é que os obstáculos criados por jogos lúdicos não são conduzidos pelo ser humano sempre do mesmo modo, pois, quando estão diante de regras jurídicas, os seres humanos costumam depositar fé no negócio jurídico com muito mais convicção e responsabilidade do que na brincadeira de um jogo. Os jogos são constituídos por regras que estabelecem obstáculos para dificultar o alcance do objetivo, o que não faz sentido no caso da linguagem e nem no caso dos direitos. As regras têm que promover ou facilitar a eficiência, e esse nem sempre é o caso dos jogos. Ou seja, quando realizamos um negócio jurídico - como a compra e venda da propriedade privada -, não estamos brincando como em um jogo. Estamos considerando e levando a sério as cláusulas daquele contrato em específico.

Podemos, também, pensar os direitos como permissões e proibições dentro de sistemas de regras que não são propriamente jurídicas ou legais, como ocorre em qualquer compromisso agendado entre amigos ou membros da família, ou até mesmo em um jogo, como é o caso do futebol: "[...] direitos deste tipo são em si e por si pré-morais e pré-legais." (TUGENDHAT, 2003, p. 341). No caso de um jogo, as regras desse sistema específico de obrigações contextualizam os deveres e direitos relativos a cada time, especificam as jogadas que cada jogador está autorizado a praticar, atribuindo direitos e liberdades, bem como deveres e exigências mínimas que cada adversário deve praticar para garantir o fair play. Como em um jogo, qualquer acordo entre pessoas no senso comum gera direitos e deveres, porém os direitos e deveres gerados naquela ocasião são específicos apenas para aquelas partes, ou para os jogadores e times daquela partida ou daquele torneio em específico, são direitos oriundos de obrigações interpessoais; isso tudo desde que esses supostos direitos não sejam expressamente proibidos por lei. 
No caso dos direitos concedidos em obrigações extralegais, como um encontro agendado entre amigos, esses "direitos" existem apenas como palavras ao vento e se sustentam, como se costuma dizer no senso comum, à base do fio do bigode, por laços autênticos e espontâneos de cooperação, sem que os seus participantes possam contar com o reforço que o ordenamento jurídico pode dar às suas obrigações. Observe que a palavra "direitos" foi grifada para ressaltar o uso que as pessoas fazem dela no senso comum, pois seria leviano afirmar que essas pequenas promessas do dia a dia são suficientes para gerar direitos legais. O que se pode dizer é que as pessoas usam a linguagem dos direitos mesmo em contextos que não são jurídicos. Como esses direitos nascem diretamente entre as partes específicas da relação, acabam também por existirem sem maiores garantias e segurança de que serão efetivamente cumpridos e respeitados. São direitos tão específicos para os interesses daquelas pessoas em questão que, talvez, não haja mesmo nenhuma condição de serem impostos por uma ordem legal.

Com base na correlação entre direitos e deveres, o jogo da promessa mostra que os direitos são manuseados por pessoas - seres humanos entre si ou Estados na comunidade internacional - que realizam pactos e acordos, explicitando o significado dos denominados direitos pessoais ou especiais, que são compreendidos em oposição aos direitos gerais. Os direitos especiais produzem efeitos apenas para as pessoas envolvidas diretamente na relação jurídica, como em uma dívida, que só pode ser cobrada do devedor em específico (ou, no máximo, do seu fiador), que, por exemplo, pegou dinheiro emprestado com o credor. Mas, em contraposição aos direitos especiais, não poderíamos falar em direitos gerais? Não poderíamos pensar em direitos que ultrapassam as fronteiras das partes envolvidas e são aplicáveis contra todas as pessoas do mundo? Os direitos humanos não seriam direitos gerais?

\subsection{Direitos in personam e direitos in rem}

Para esclarecer esse ponto, é relevante trazer à tona a distinção do jurista Welsey Hohfeld entre direitos in personam e direitos in rem, segundo a qual se especifica quem é o destinatário do direito e, portanto, em quem recairão os efeitos da obrigação. No primeiro caso, também denominado obrigações in personam, estamos diante daqueles direitos e deveres válidos apenas para as partes envolvidas na obrigação. "A característica distintiva dos direitos in personam é que eles correlacionam deveres específicos de determinados indivíduos" (FEINBERG, 1974, p. 91, grifo do autor) e, nesse sentido, são válidos para uma pessoa em específico ou para um grupo determinado de pessoas: "[...] um direito exclusivo que reside em uma pessoa (ou grupo de pessoas) e dispõe contra uma única pessoa (ou único grupo de pessoas), [...] direitos que valem, respectivamente, contra algumas pessoas definidas." (HOHFELD, 2001, p. 53, tradução nossa). ${ }^{6}$ Nesse caso, diz-se que o sujeito X possui um direito e pode reivindicá-lo só, e somente só, em relação ao destinatário Y - e a mais ninguém.

\footnotetext{
6 "[...] a unique right residing in a person (or group of persons) and availing against a single person (or single group of persons); [...] rights availing respectively against a few definite persons." (HOHFELD, 2001, p. 53).
} 
O destinatário do direito, a quem o titular irá provocar os efeitos da obrigação, está claramente delimitado nas obrigações pessoais e pode ser apontado com o dedo, referindo-se, assim, a quem deverá prestar a contrapartida para a realização do direito, que pode ser uma pessoa física ou uma pessoa jurídica, como uma sociedade anônima ou limitada, como as próprias instituições burocráticas do Estado, e assim por diante. Os juristas geralmente dizem que os efeitos desse tipo de obrigação são considerados inter partes, pois dizem respeito apenas às partes envolvidas, como na cobrança de uma dívida segundo a qual o credor cobra e executa o título a partir de um devedor determinado.

Já no caso das obrigações in rem, estamos diante daqueles direitos e deveres válidos para "todas" as pessoas, e não somente para as pessoas que compõem diretamente a relação jurídica - e é aqui que os problemas e paradoxos relacionados aos direitos humanos ganharão consistência, pois não queremos, enquanto seres humanos, pensá-los sob a ótica dos direitos especiais.

Antes de adentrarmos nessa discussão, é preciso esclarecer que os direitos in rem não são, como o seu próprio nome poderia sugerir, direitos contra as coisas, ${ }^{7 ~ "[. . .] ~ u m ~ d i r e i t o ~ i n ~ r e m ~ n a ̃ o ~ e ́ ~ n e-~}$ cessariamente uma relação para, ou relativo a, uma coisa, i. e., um objeto tangível." (HOHFELD, 2001, p. 64, grifo do autor, tradução nossa), ${ }^{8}$ pois, conforme ressalta Hohfeld (grifos do autor, tradução nossa), 9 "[...] todos os direitos in rem são contra pessoas [...]" (HOHFELD, 2001, p. 56), são direitos oponíveis contra "todas" as pessoas, inclusive aquelas que não compõem a relação jurídica em específico. Afirma Simmonds (2001, p. xvi, grifo do autor, tradução nossa):

Esta é frequentemente considerada uma distinção entre os direitos sobre as coisas e direitos contra as pessoas, mas essa interpretação é claramente inaceitável. [...] direitos só podem ter consequências jurídicas para outras pessoas, e portanto, só podem ser direitos contra outras pessoas, não sobre as coisas. ${ }^{10}$

Ter ou possuir um direito in rem é possuir um direito válido contra todas as pessoas de um determinado grupo de indivíduos, de uma comunidade ou de um conjunto de cidadãos, quem sabe até

\footnotetext{
Prossegue Hohfeld (2001, p. 64, grifo do autor, tradução nossa): "[...] agora deve ser razoavelmente claro que a tentativa de conceber um direito in rem como um direito contra uma coisa deveria ser abandonada como intrinsecamente instável, como totalmente desacreditada de acordo com os bons usos, e, finalmente, como muito provável em confundir e enganar." "[...] it must now be reasonably clear that the attempt to conceive of a right in rem as a right against a thing should be abandoned as intrinsically unsound, as thoroughly discredited according to good usage, and, finally, as all too likely to confuse and mislead." (HOHFELD, 2001, p. 64, grifo do autor)]. Diz Jones (1994, p. 15, grifo do autor, tradução nossa): "Outra distinção útil é entre 'direitos in personam' e 'direitos in rem'. A mesma distinção é por vezes identificada como aquela entre 'pessoal' e 'real' ou aquela entre direitos 'relativos' e 'absolutos'. Nenhum desses rótulos é muito útil como um guia para o conteúdo da distinção e alguns são positivamente enganosos. Simplificando, um direito in personam é um direito realizado contra uma determinada pessoa ou pessoas, enquanto um direito in rem é realizado contra as pessoas em geral." ["Another useful distinction is between 'rights in personam' and 'rights in rem'. The same distinction is sometimes identified as that between 'personal' and 'real' rights or that between 'relative' and 'absolute' rights. None of those labels is very helpful as a guide to the content of the distinction and some are positively misleading. Simply stated, a right in personam is a right held against a specific person or persons, while a right in rem is one held against people at large." (JONES, 1994, p. 15, grifo do autor)].

8 "[...] a right in rem is not necessarily one relating to, or concerning, a thing, i. e., a tangible object." (HOHFELD, 2001, p. 64, grifo do autor).

9 "[...] all rights in rem are against persons [...]" (HOHFELD, 2001, p. 56, grifo do autor).

10 "This is often regarded as a distinction between rights over things and rights against persons, but such an interpretation is clearly unacceptable. [...] rights can only have juridical consequences for other persons, and can therefore only be rights against other persons, not things." (SIMMONDS, 2001, p. xvi, grifo do autor).
} 
de uma comunidade internacional que possa evidenciar a existência de direitos universais. Diz Hohfeld (2001, p. 53, grifo do autor, tradução nossa), ao classificar o direito in rem como direito multital:

Um direito multital, ou exigência (direito in rem), é sempre aquele sobre uma grande classe de direitos fundamentalmente semelhantes ainda que separados, efetivos e potenciais, residente em uma única pessoa (ou único grupo de pessoas), mas valendo, respectivamente, contra pessoas que constituem uma classe muito grande e indefinida de pessoas. ${ }^{11}$

Os direitos in rem são, pois, direitos contra todas as pessoas do mundo, como afirma Feinberg (1974, p. 91), são direitos "[...] sustentados não contra uma pessoa ou pessoas específicas e designáveis, mas contra o "mundo em geral." Nesse ponto da investigação, se já é difícil apontar com clareza quem é o titular do direito, mais difícil ainda será especificar o seu destinatário, o qual, muitas vezes, remete a "todas" as pessoas em um sentido generalíssimo - ou universal, ou, ainda, absoluto - e, logo, não se consegue identificar para onde aponta a direção normativa que provém da exigência por direitos. Não se consegue individualizar quem é que deve cumprir o dever, o que pode deixar o detentor do direito a ver navios, sem saber como a sua exigência será suprida. Tratam-se, pois, daquelas obrigações que os juristas denominam erga omnes, pois provocam efeitos a todas as pessoas, inclusive aquelas que não compõem a relação jurídica e, desse modo, dizem respeito a uma relação que não produz efeitos somente aos envolvidos. Continua Hohfeld (2001, p. 53-54, grifo do autor, tradução nossa):

Provavelmente, todos concordam, substancialmente, sobre o sentido e o significado de um direito in personam, como explicado; e é fácil de dar alguns exemplos preliminares: Se B deve a A mil dólares, A tem um direito afirmativo in personam, ou direito paucital, que $\mathrm{B}$ deve transferir para $\mathrm{A}$ a propriedade legal desta quantidade de dinheiro. Se, para colocar uma situação contrastante, A já tem um título a mil dólares, os seus direitos contra os outros em relação aos mesmos são direitos multital, ou direitos in rem. No primeiro caso, o dinheiro é devido a $\mathrm{A}$, em outro caso é de propriedade de A. Se Y tem contratado trabalhar para X durante os seis meses seguintes, $\mathrm{X}$ tem um direito afirmativo in personam que $\mathrm{Y}$ deve prestar tal serviço, conforme acordado. ${ }^{12}$

Simmonds (2001) também aborda a distinção entre os direitos que se dirigem a uma determinada pessoa ou classe de pessoas e os direitos que se dirigem a todas as pessoas ou a uma classe indefinida de pessoas.

Um direito pessoal, ou exigência (direito in personam), é ou um direito único residindo em uma pessoa (ou grupo de pessoas) e valendo contra uma única pessoa (ou único grupo de pessoas), ou então é um dos poucos direitos fundamental-

\footnotetext{
11 "A multital right, or claim, (right in rem) is always one of a large class of fundamentally similar yet separate rights, actual and potential, residing in a single person (or single group of persons) but availing respectively against persons constituting a very large and indefinite class of people." (HOHFELD, 2001, p. 53, grifo do autor).

12 "Probably all would agree substantially on the meaning and significance of a right in personam, as just explained; and it is easy to give a few preliminary examples: If $B$ owes $A$ a thousand dollars, $A$ has an affirmative right in personal, or paucital right, that $B$ shall transfer to $A$ the legal ownership of that amount of money. If, to put a contrasting situation, A already has title to one thousand dollars, his rights against others in relation thereto are multital rights, or rights in rem. In the one case the money is owed to $A$; in the other case it is owned by $A$. If $Y$ has contracted to work for $X$ during the ensuing six months, $X$ has an affirmative right in personam that $Y$ shall render such service, as agreed." (HOHFELD, 2001, p. 53-54, grifo do autor).
} 
mente semelhantes, ainda que separadas, valendo, respectivamente, contra algumas pessoas definidas. [...] Um direito real, ou exigência (direito in rem), é sempre aquele sobre uma grande classe de direitos fundamentalmente semelhantes ainda que separados, efetivos e potenciais, residindo em uma única pessoa (ou grupo único de pessoas), mas valendo, respectivamente, contra pessoas que constituam uma classe muito grande e indefinida de pessoas. (SIMMONDS, 2001, p. xvii, grifo do autor, tradução nossa). ${ }^{13}$

É justamente a partir das obrigações in rem que devemos - ou melhor, que queremos, enquanto seres humanos - pensar os direitos humanos, pois, ao menos em tese, são direitos aos quais todos os seres humanos devem satisfação e respeito, conforme a intuição de Kant ${ }^{14}$ ao mostrar que alguns direitos são universais e dizem respeito à nossa humanidade. São direitos que só poderiam existir em razão de, no mínimo, uma ordem internacional. Assim, as obrigações gerais são importantes porque nos levam a pensar que uma definição estrita dos direitos não dá conta dos direitos humanos, e, em razão dessas limitações, temos que recorrer aos denominados direitos gerais.

O exemplo mais ilustrativo de direitos contidos em obrigações in rem diz respeito às liberdades negativas, que foram declaradas, no século XVIII, como o uso e o gozo da propriedade privada; liberdades às quais o titular tem o direito de não sofrer interferências no exercício da sua liberdade. "Eu tenho, por exemplo, o direito de não ser lesado, e este ius in rem significa que todos os outros são obrigados a não me lesar." (TUGENDHAT, 2003, p. 348). Trata-se, pois, de um direito negativo, "[...] um direito a omissões ou abstenções de outras pessoas." (FEINBERG, 1974, p. 92). Ou seja, o dever - se é que podemos chamá-lo assim - que surge da exigência é uma espécie de dever negativo ou omissivo, segundo o qual o destinatário deve se omitir ou não deve agir para interferir no direito do titular. $\mathrm{O}$ detentor do direito, isto é, o proprietário, possui o direito de exercer livremente o uso, o usufruto e a fruição da coisa que legitimamente lhe pertence, mas, para tanto, necessita que os outros (isto é, "todas" as outras pessoas, em um sentido absoluto) não interfiram na sua propriedade privada. Segundo Jones (1994, p. 15, grifo do autor, tradução nossa), "[...] exigências-direitos negativas são direitos in rem." 15 O mesmo ocorre com tantos outros direitos denominados "individuais", ${ }^{16}$

\footnotetext{
13 "A paucital right, or claim (right in personam), is either a unique right residing in a person (or group of persons) and availing against a single person (or single group of persons); or else it is one of a few fundamentally similar, yet separate, rights availing respectively against a few definite persons. [...] A multital right, or claim (right in rem), is always one of a large class of fundamentally similar yet separate rights, actual and potential, residing in a single person (or single group of persons) but availing respectively against persons constituting a very large and indefinite class of people." (SIMMONDS, 2001, p. xvii, grifo do autor).

14 Ver Perpetual peace (1795), de Immanuel Kant (1957).

15 "[...] negative claim-rights are rights in rem." (JONES, 1994, p. 15, grifo do autor).

16 Segundo Hohfeld (2001, p. 53-54, grifo do autor, tradução nossa), é possível falarmos em direitos in personam negativos: "Por outro lado, pode ocasionalmente serem direitos in personam de um teor ou conteúdo negativo. Assim, se K, um cantor de ópera distinto, contrata com J que o primeiro não irá nos próximos três meses cantar em qualquer ópera rival, J tem um direito negativo in personam contra $\mathrm{K}$, e este último tem um dever correlato negativo. Neste, como em outros casos de direitos no sentido de exigências, o direito de J é apenas uma fase da relação total entre J e K, bem como o dever de K é outra fase da mesma relação, - isto é, a inteira relação 'direito-dever' pode ser vista de ângulos diferentes." ["On the other hand, there may occasionally be rights in personal of a negative tenor or content. Thus if $K$, a distinguished opera singer, contracts with $J$ that the former will not for the next three months sing at any rival opera house, $J$ has a negative right in personal against $K$; and the latter is under a correlative negative duty. In this, as in other cases of rights in the sense of claims, the right of $J$ is but one phase of the total relation between $J$ and $K$, and the duty of $K$ is another phase of the same relation, - that is, the whole 'right-duty' relation may be viewed from different angles." (HOHFELD, 2001, p. 53-54, grifo do autor)].
} 
ou, ainda, direitos de primeira dimensão, como o direito de ir e vir, o direito de expressar sua opinião ou pensar livremente, entre outros. No caso do Direito Penal, as liberdades e garantias individuais do acusado podem explicitar a questão, pois o acusado passa a ter o direito de não ser impedido a dar razões contra a sua acusação e sua prisão por meio do habeas corpus.

\section{0 caso dos direitos gerais}

O fato é que no mundo ocidental "queremos" possuir direitos que digam respeito à nossa humanidade e, quando evocamos a palavra "direito" em algumas reivindicações por direitos humanos, principalmente por grupos e ativistas desses direitos, reivindicamos e exigimos os direitos humanos a partir de um sentido universal e da representação daqueles direitos "gerais"17 que são de todos os seres humanos. Não é à toa que, quando se fala em direitos humanos, logo se pensa nos direitos que são de todo e qualquer ser humano, isto é, os beneficiários desse tipo de direito são "todos" os seres humanos do universo - o que, à primeira vista, pode parecer tautológico ou um contrassenso para aquele que considera o direito algo possuído por alguém, mais especificamente por uma pessoa determinada, que se pode apontar com o dedo, quando, por exemplo, se diz "este" homem ou "aquele" grupo de pessoas "têm" ou "possuem" um determinado direito.

No caso de alguns direitos humanos, parece tão difícil dizer quem é exatamente o detentor do direito, que, como evasiva, costuma-se responder à indagação com subterfúgios do tipo "todos os seres humanos possuem direitos em razão de sua humanidade ou do fato de sermos todos seres humanos." Conforme diz Nickel (2007, p. 37, tradução nossa): “[...] a reflexão sobre a ideia de que os titulares de direitos humanos são simplesmente todas as pessoas revela que esta resposta é muito ampla." ${ }^{18} \mathrm{O}$ que, então, queremos dizer quando falamos que os direitos humanos são gerais, universais e absolutos?

\subsection{Os direitos humanos como direitos gerais}

O caso dos direitos gerais torna o problema ainda mais delicado e paradoxal porque aborda direitos que superam a relação obrigacional entre as partes e, assim, nem sempre sabemos quem os possui, nem contra quem esses direitos podem ser reivindicados. Verificamos, apenas, que temos o costume de afirmar que todos os seres humanos possuem um determinado direito em razão de sua humanidade, embora, muitas vezes, seja muito difícil, talvez até impossível, apontar em quem recai o dever que corresponde ao direito.

\footnotetext{
17 Sobre os direitos gerais, conferir: Hart (1955, p. 187).

18 "[...] reflection on the idea that the holders of human rights are simply all people reveals that this answer is too broad." (NICKEL, 2007, p. 37).
} 
A propósito disso, as circunstâncias que envolvem as crianças e as pessoas com necessidades especiais demonstram que o problema não é tão simples assim para se resolver com generalizações do tipo "todos" os seres humanos possuem o direito e a liberdade de escolher uma prática religiosa ou um parceiro sexual. Quando reivindicamos esses direitos certamente não estamos nos referindo aos menores e aos incapazes, e, portanto, não podemos falar a sério em "todos" os seres humanos. Continua Nickel (2007, p. 37, tradução nossa): "[...] alguns direitos são assegurados apenas para cidadãos adultos, não para todas as pessoas. [...] Além disso, os direitos das pessoas que são muito jovens, severamente deficientes, em coma, ou senis são justamente limitados."19 Outro exemplo disso é que as crianças não possuem o direito "geral" ao voto.

A mesma constatação pode ser feita ao seu destinatário, visto que os direitos humanos não apenas são possuídos por todos os seres humanos, mas também se dirigem a todos eles. Nesse ponto, se já era difícil apontar o portador de um direito humano, mais grave e complicado ainda será inferir em quem recaem esses direitos, quem são os seus destinatários. A demanda por endereçados custa muito caro para os projetos de fundamentação dos direitos humanos, talvez até mais do que a universalização do portador, pois alguns desses direitos, aqueles que não se encontram ainda positivados em tratados e protocolos internacionais, correm o risco de nunca serem respeitados, pois, se não sabemos ao certo a quem é devido o dever de satisfazer a exigência, fica quase impossível responsabilizar o seu ofensor, e a consequência disso é que o direito humano em questão, por si só, restará violado. O que se quer dizer com isso é que não é uma tarefa tão simples assim determinar o destinatário dos direitos humanos, o que pode, muitas vezes, confundir o titular do direito ou até os manifestantes e ativistas de direitos humanos que, mesmo ao estarem em posição moral e jurídica para produzir exigências, não sabem ao certo contra quem irão exigir esses direitos.

Nesse sentido, a obrigação à qual estão vinculadas as partes parece implodir a partir da afirmação de que possuímos direitos que são de "todos", direitos que "todos" possuem em razão de sua humanidade, e, assim por diante, quando se ultrapassam os limites da relação obrigacional, universalizando-a a partir dos seus elementos básicos, como o possuidor ou o destinatário. No fundo, os direitos humanos instigam a nossa frágil imaginação, fazendo com que os seres humanos queiram ser reconhecidos como membros iguais de uma comunidade ao possuírem pontos em comum com outros seres humanos. Seres humanos querem, assim, possuir direitos, mesmo se esses direitos não existirem; eles querem possuir direitos universais, isto é, direitos que todos possuiriam e aos quais todos estariam obrigados; querem, enfim, possuir direitos que transcendem o âmbito das obrigações especiais e não se resumem a nenhuma relação jurídica em específico.

É justamente aí que os problemas vão surgir e se agravar, se pensarmos os direitos humanos a partir da perspectiva do ius in rem ou dos direitos gerais, principalmente quando verificarmos que

19 "[...] some rights are held only by adult citizens, not by all persons. [...] Further, the rights of people who are very young, severely retarded, comatose, or senile are justifiably limited." (NICKEL, 2007, p. 37). 
eles não se enquadram na estrutura dos direitos especiais ou in personam, nem se ajustam à lógica dos direitos e deveres fixados em um ordenamento jurídico. Em tese, os direitos humanos não dependem de um acordo ou contrato entre duas partes, pois eles são direitos controvertidos para se fazer um contraponto aos direitos especiais que nascem das obrigações extralegais, não apenas porque são anteriores à lei, mas, principalmente, porque são referidos como direitos gerais e se aplicam a todos os seres humanos, independentemente de nos referirmos a esta ou aquela relação obrigacional.

\subsection{0 exercício dos direitos}

Explanemos o caso do direito ao voto, tomado amplamente como um direito fundamental para instituir a regra democrática pela qual todos os cidadãos podem participar das escolhas políticas do seu país. Com esse exemplo, podemos ressaltar a distinção entre direitos gerais e direitos pessoais, pois o voto é um direito geral ao mesmo tempo que depende completamente de uma ordem legal. O voto - ou o direito "geral" ao voto - por parte das mulheres, por exemplo, só pode ser exercido exclusivamente como um "direito legal" e contextualizado dentro dos países que, por exemplo, integram as Nações Unidas, embora ainda existam países que, em sua soberania, não autorizam o exercício desse direito.

Esses exemplos ressaltam a distinção entre o direito geral ao voto e o direito específico de votar nas próximas eleições e é interessante porque nos permite pensar aqueles direitos, ou exigências por direitos, que só podem ser exercidos dentro de um sistema legal no qual figura como um direito específico, e, quando não está incorporado no ordenamento jurídico deste ou daquele país, não pode ser posto em prática, nem mesmo à sombra da ilegalidade. No caso do voto, o máximo que as mulheres daquele país podem fazer é produzir uma exigência por direito no plano, digamos assim, moral, requerendo que o seu direito geral ao voto se torne um direito legal. Mas, até segunda ordem, elas não possuem o direito especial de votar já no próximo pleito.

Podemos também trazer à tona o exemplo de um direito exercível mesmo à luz da distinção entre direitos especiais e direitos gerais, como é o caso da liberdade religiosa. Todos os seres humanos possuem a liberdade de culto, fé ou crença religiosa, independentemente da prática religiosa imposta por determinado país. Todos possuem, aliás, o direito de viver sob a batuta de um Estado laico, mas, por certo, muitos países impõem ainda hoje uma só prática religiosa ao punir o exercício da fé dissidente. Mesmo sob tamanha repressão, poderíamos dizer que os cidadãos daquele país possuem o direito e a liberdade a qualquer prática religiosa? Seriam realmente direitos esses direitos "gerais"? Poderiam eles existir?

O ponto relevante desse exemplo é que o direito "geral" à liberdade religiosa (em oposição ao direito legal e específico) pode ser exercido na clandestinidade, sem que as autoridades tomem ciência do fato - o que comprova a tese de que um direito é mais forte se exercido, mas o seu exercício não é uma condição necessária para se dizer o que é um direito provocado a partir do fenômeno moral. 
Foquemos no tema do aborto e da eutanásia, por exemplo, desses direitos que também podem se constituir como exercíveis na esfera moral, visto que, mesmo com a proibição legal, muitas grávidas efetuam o aborto clandestino ou, no caso da eutanásia, muitos pacientes em estado terminal tiram a sua própria vida com o auxílio de terceiros, deixando subentendido que a causa mortis foi um motivo diferente. São exemplos que demonstram que falamos em "direitos" para justificar algumas de nossas exigências morais, mesmo quando esses direitos não são reconhecidos por uma autoridade competente; ou quando não estão incorporados à prática social; ou mesmo quando não podem ser exercidos porque a sua prática constituiria uma ilegalidade. Nem mesmo a aceitação social é uma condição necessária para falarmos em direitos, e o caso dos direitos exigidos a partir de obrigações morais demonstra justamente isso, conforme esclarece Feinberg (1992, p. 152, grifo do autor, tradução nossa) em sua defesa dos direitos morais: "[...] há uma distinção entre os direitos morais que são exercíveis até mesmo antes do reconhecimento legal e aqueles que não podem ser exercidos antes de serem transformados em lei." ${ }^{20}$

Isso significa que não só exigimos direitos "gerais" que não estão prescritos em lei, como também tentamos colocá-los em prática, exercendo-os como se direitos o fossem, e, em razão disso, nem sempre se pode dizer que alguém possui um direito apenas por se referir aos direitos outorgados em razão de alguma legislação específica ou aos direitos que estão incorporados em práticas sociais. Por incrível que pareça, nem mesmo o seu exercício é um fator determinante para definir o que é um direito, visto que usamos essa palavra até mesmo quando o direito não pode ser exercido, como é o caso daqueles que dependem de um sistema jurídico para serem instituídos, como, por exemplo, o direito a um julgamento imparcial, ou o direito ao devido processo legal ou, ainda, o direito ao voto. Esses direitos não podem existir na clandestinidade, pois, para serem colocados em ação, carecem de uma ordem legalmente constituída e sustentada por um sistema de sanções jurídicas para eventuais violações desses direitos.

\section{Considerações finais}

Os direitos gerais são casos curiosos de se analisar, pois temos todas as evidências de que não existem direitos gerais, universais e absolutos, mas, mesmo assim, quando reivindicamos os direitos humanos, essa reivindicação é produzida a partir de um ponto de vista universalista. Os direitos humanos são possuídos por todos os seres humanos e podem ser reivindicados contra todos e contra o mundo, dito assim, de um modo generalíssimo. Eles são enunciados e reivindicados como se fossem gerais, embora não se possa dizer que esses direitos sejam gerais ou universais em si mesmos.

Diante de contraexemplos, não podemos negar que as características da dogmática dos direitos começam a ficar nebulosas e já não esclarecem muito bem o sentido dos direitos humanos

20 "[...] there is a distinction between those moral rights that are exercisable even prior to legal recognition and those which cannot be exercised before being enacted into law." (FEINBERG, 1992, p. 152, grifo do autor). 
ou mesmo dos direitos reivindicados como se fossem direitos gerais, ao contrário do que ocorre com os direitos legais. Tais direitos são "exigências" que um ser humano faz para o outro sob o pano de fundo da moralidade, em especial quando reivindica direitos contra o Estado ou a comunidade internacional. Essas exigências são enunciadas como se fossem direitos gerais que transcendem os limites específicos das obrigações especiais ou pessoais, pois, das duas, uma: ou passamos a defender cegamente a existência de direitos universais, de modo a usufruir dos recursos da metafísica tradicional para universalizar os direitos humanos a partir de características intrínsecas e inerentes à natureza humana - o que nos revelará o principal erro ao qual está sujeita uma teoria de fundamentação dos direitos humanos, ou, então, passamos a aceitar a tese de que os direitos humanos só fazem sentido se abordados a partir de obrigações específicas, no sentido de que os direitos gerais exigidos são produzidos para fortalecer um dos lados de uma obrigação específica.

\section{Referências}

BOBBIO, Norberto. A era dos direitos. Rio de Janeiro: Elsevier, 2004.

FEINBERG, Joel. Filosofia social. Rio de Janeiro: Zahar, 1974.

FEINBERG, Joel. In Defense of Moral Rights. Oxford Journal of Legal Studies, Oxford, v. 12, n. 2, p. 149-169, 1992. Disponível em: <http://ojls.oxfordjournals.org/content/12/2/149.citation>. Acesso em: 17 mar. 2012.

GILBERT, Margaret. Scanlon on promissory obligation: the problem of promisees' rights. The Journal of Philosophy, v. 101, n. 2, p. 83-109, fev. 2004. Disponível em: < http://www.jstor.org/stable/3655658>. Acesso em: 09 jul. 2012.

HARE, Richard. The promising game. In: FOOT, Philippa (Ed.). Theories of ethics. London: Oxford University Press, 1967. Cap. VIII. p. 115-127.

HART, Herbert Lionel Alphonsus. Are There Any Natural Rights? The Philosophical Review, Duke University Press, v. 64, n. 2, p. 175-191, abr. 1955. Disponível em: < http://www.jstor.org/stable/2182586>. Acesso em: 12 fev. 2012.

HOHFELD, Wesley Newcomb. Fundamental legal conceptions as applied in judicial reasoning. Edited by David Campbell and Philip A. Thomas, with an introduction by Nigel E. Simmonds. Ashgate: Aldershot, 2001.

JONES, Peter. Rights: issues in political theory. Hampshire: Palgrave; Macmillan Press, 1994.

KANT, Immanuel. Perpetual peace. Indianópolis: Bobbs-Merrill, 1957.

NICKEL, James W. Making Sense of Human Rights. 2. ed. Malden: Blackwell, 2007.

SIMMONDS, Nigel. Introduction. In: HOHFELD, Wesley Newcomb. Fundamental legal conceptions as applied in judicial reasoning. Edited by David Campbell and Philip A. Thomas. Ashgate: Aldershot, 2001. p. ix-xxix. (Classical jurisprudence series). 
TUGENDHAT, Ernst. Lições sobre ética. 5. ed. Petrópolis: Vozes, 2003.

Data da submissão: 21 de fevereiro de 2016 Avaliado em: 09 de maio de 2017 (AVALIADOR A) Avaliado em: 09 de maio de 2017 (AVALIADOR B) Avaliado em: 12 de maio de 2017 (AVALIADOR C) Aceito em: 12 de abril de 2018 